\title{
MEMS reliability in shock environments
}

\author{
Danelle M. Tanner, Jeremy A. Walraven, Karen Helgesen, Lloyd W. Irwin, \\ Fredrick Brown, Norman F. Smith, and Nathan Masters \\ Sandia National Laboratories, P.O. Box 5800, MS 1081, Albuquerque, NM 87185-1081 \\ http://www.mems.sandia.gov \\ email: tannerdm@sandia.gov
}



\begin{abstract}
In order to determine the susceptibility of our MEMS (MicroElectroMechanical Systems) devices to shock, tests were performed using haversine shock pulses with widths of 1 to $0.2 \mathrm{~ms}$ in the range from $500 \mathrm{~g}$ to $40,000 \mathrm{~g}$. We chose a surface-micromachined microengine because it has all the components needed for evaluation: springs that flex, gears that are anchored, and clamps and spring stops to maintain alignment. The microengines, which were unpowered for the tests, performed quite well at most shock levels with a majority functioning after the impact.

Debris from the die edges moved at levels greater than $4,000 \mathrm{~g}$ causing shorts in the actuators and posing reliability concerns. The coupling agent used to prevent stiction in the MEMS release weakened the die-attach bond, which produced failures at $10,000 \mathrm{~g}$ and above. At $20,000 \mathrm{~g}$ we began to observe structural damage in some of the thin flexures and 2.5-micron diameter pin joints.

We observed electrical failures caused by the movement of debris. Additionally, we observed a new failure mode where stationary comb fingers contact the ground plane resulting in electrical shorts. These new failures were observed in our control group indicating that they were not shock related.
\end{abstract}

\section{INTRODUCTION}

Reliability studies and predictions are becoming crucial to the success of MEMS as they reach commercialization. Cunningham et al. has addressed the issue of shock robustness in silicon microstructures [1]. They evaluated different microbeam designs and found that those with reduced stress distributions were more robust to the effects of shock. Brown et al. performed extensive experiments on MEMS sensors, including shock, vibration, temperature cycling, and flight tests on artillery projectiles [2]. They saw promising results on automobile-grade accelerometers. However, sensors differ from microactuators in that they do not have rubbing surfaces. Surfaces in intimate contact during the environmental test may be at risk. This was demonstrated in reports on humidity effects and wear $[3,4]$.

Microactuators are used to drive many different types of devices from gear trains to pop-up mirrors [5]. Microactuators are typically complex with beams, comb fingers, linkages, gears, and springs. Each of these elements could be damaged by a shock impact. The objective of this study was to determine what elements, if any, of the microengine are susceptible to shock, with the understanding that the results could be applied to other MEMS actuators.

\section{EXPERIMENTAL APPROACH}

This study used the electrostatically driven microactuator (microengine) developed at Sandia National Laboratories [6]. The microengine consists of orthogonal linear comb drive actuators mechanically connected to a rotating gear as seen in Figure 1. By applying voltages, the linear displacement of the comb drives was transformed into circular motion. The $\mathrm{X}$ and $\mathrm{Y}$ linkage arms are connected to the gear via a pin joint. The gear rotates about a hub, which is anchored to the substrate.

It was our intention to perform experiments with higher and higher shock levels until failures were observed. Following this approach, we would determine any MEMS susceptibility to shock.

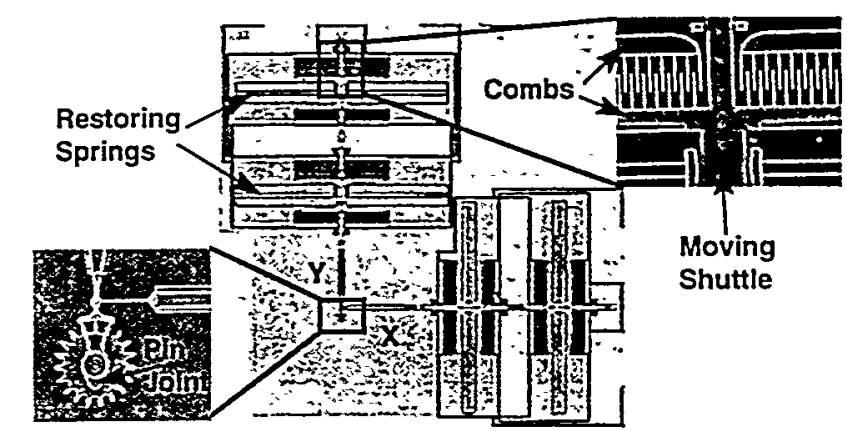

Figure 1. Sandia microengine with expanded views of the comb drive (top right) and the rotating gear (bottom left).

\section{Calculations}

In this discussion, the vulnerabilities to shock environments were calculated using simple models and Newtonian physics. Damping in the air environment was not included but may be a factor in reducing the shock effects. These calculations are most certainly worst case.

The first step is to calculate the mass of the moving structures. Figure 2 shows the comb, shuttle, and spring structure. The structure is anchored in four places near the inner guides circled in the figure. The mass was calculated as the product of area, thickness, and density of polysilicon and is shown in Table 1. Each structure is composed of two separate polysilicon beams, which are anchored together. The lower beam is $2.5-\mu \mathrm{m}$ thick and the upper beam is $2.25-\mu \mathrm{m}$ thick. The density of polysilicon is $2.33 \mathrm{~g} / \mathrm{cm}^{2}$ or $2.33 \mathrm{x}$ $10^{-6} \mu \mathrm{g} / \mu \mathrm{m}^{3}$ 


\section{DISCLAIMER}

This report was prepared as an account of work sponsored by an agency of the United States Government. Neither the United States Government nor any agency thereof, nor any of their employees, make any warranty, express or implied, or assumes any legal liability or responsibility for the accuracy, completeness, or usefuiness of any information, apparatus, product, or process disclosed, or represents that its use would not infringe privately owned rights. Reference herein to any specific commercial product, process, or service by trade name, trademark, manufacturer, or otherwise does not necessarily constitute or imply its endorsement, recommendation, or favoring by the United States Government or any agency thereof. The views and opinions of authors expressed herein do not necessarily state or reflect those of the United States Government or any agency thereof. 


\section{DISCLAIMER}

Portions of this document may be illegible in electronic image products. Images are produced from the best available original document. 


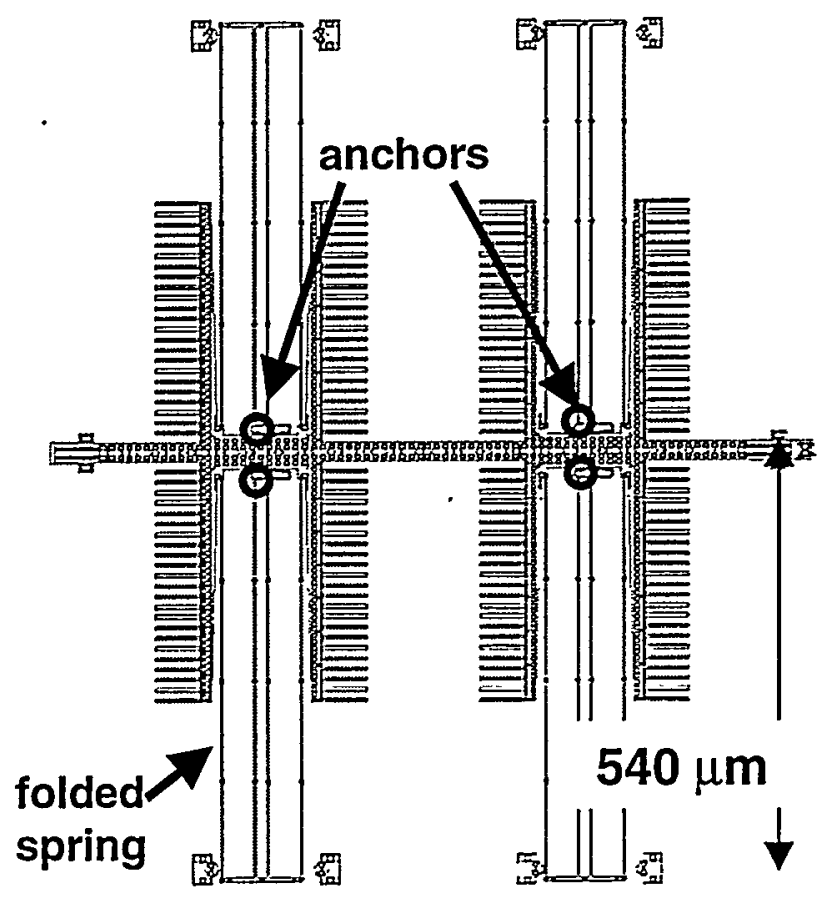

Figure 2. The moving components of the microengines actuator include combs, shuttle, and springs. The arrows and circles indicate where the springs are anchored.

Table 1. Mass of moving structure

\begin{tabular}{|l|l|l|l|l|}
\hline & $\begin{array}{l}\text { Area } \\
(\mu \mathrm{m})^{2}\end{array}$ & $\begin{array}{l}\text { Mass } \\
(\mu \mathrm{g})\end{array}$ & No. & $\begin{array}{l}\text { Full mass } \\
(\mu \mathrm{g})\end{array}$ \\
\hline Shuttle & 30,866 & .342 & 1 & .342 \\
\hline Comb & 5,760 & .064 & 8 & .510 \\
\hline Springs & 4,736 & .052 & 4 & .210 \\
\hline & & & Total: & 1.06 \\
\hline
\end{tabular}

Once the mass is known, it is straightforward to calculate force due to acceleration from a shock. For example, the force from a $2000 \mathrm{~g}$, delta function shock would be

$$
F=m a=(1.06 \mu \mathrm{g})(2000 \mathrm{~g})\left(9.8 \mathrm{~m} / \mathrm{sec}^{2} \mathrm{~g}\right)=19.7 \mu \mathrm{N}
$$

The spring system in Figure 2 was modeled by first considering only one of the four folded springs connected to the shuttle. This spring is composed of two parallel inner springs, each with a spring constant $k$. The inner springs are connected in series with the two outer springs yielding a combined spring constant of $k$. The equivalent spring constant for the system is then $4 k$.

If we assume the upper and lower beams of the spring actually form a laminate instead of separate anchored beams then $k$ is

$$
k=6 E I / L^{3}
$$

where $E$ is Young's modulus generally set to $155 \mathrm{GPa}$ or .155 $\mathrm{N} / \mu \mathrm{m}^{2}$ for polysilicon, $I$ is the moment, and $L$ is the length.

The spring deflections, $\delta$, can be described by

$$
\delta=F / 4 k=F L^{3} / 24 E I
$$

The crucial factor is determining where this force acts on microengine components and how much deflection occurs before fracture. For any material, fracture occurs when the stress applied exceeds the fracture strength. For polysilicon, a conservative estimate of the fracture strength is $1.5 \mathrm{GPa}$ [7]. We can use beam-bending equations to get a handle on the effect. The stress on a simple cantilever beam is given by

$$
\sigma=F L L / 2 I
$$

$\sigma$ is the applied stress, $F$ is the force applied to the end of the cantilever of length $L, t$ is the thickness of the beam in the direction of the force, and $I$ is the moment. For a rectangular beam with width $b$,

$$
I=b t^{3} / 12
$$

Combining these equations, in the case of a rectangular beam, yields

$$
F=\sigma b r^{2} / 6 L
$$

where if the applied stress is $1.5 \mathrm{GPa}$, then this force will fracture the beam.

Now for the case of the microengine, in-the-plane shocks should be contained by spring stops and guides so we expect to see no damage. There may be stiction problems for surfaces coming into contact. However, by far the greatest vulnerability is due to an out-ofthe-plane shock. Most of the comb actuators have no constraints to motion out of the plane. For this out-of-plane motion, the force is distributed over the four-anchored spring beams that were described with an equivalent spring constant. These beams are $540-\mu \mathrm{m}$ long $(L), 4.75 \mu \mathrm{m}$ thick $(t)$, and $2 \mu \mathrm{m}$ wide $(b)$.

A large shock from the top could allow the massive shuttle and combs to rise in relation to the substrate. The springs are free to bend giving rise to misalignment and with a large enough shock could produce a spring fracture. Misalignment can occur when the combs and shuttle move away from the substrate by roughly $10 \mu \mathrm{m}$ from a shock of $400 \mathrm{~g}$. Using equation (6), a force of $21 \mu \mathrm{N}$ would break an individual spring beam. Because we have four springs, the force is distributed implying that we may see spring fracture at 84 $\mu \mathrm{N}$ or $8100 \mathrm{~g}$.

A shock from the bottom could push the shuttle, combs and springs down into the substrate. For stiction to occur, the beams must flex only $2 \mu \mathrm{m}$ towards the substrate, which could be achieved by a shock of $80 \mathrm{~g}$. A plot of the deflection equation (3) is shown in Figure 3 for accelerations of interest. Also shown on the plot are possible failure modes.

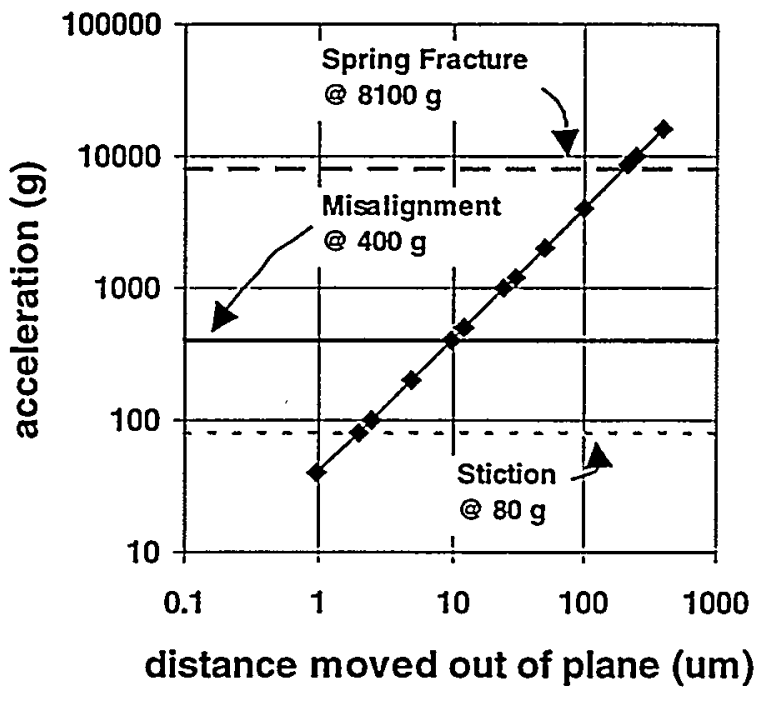

Figure 3. The plot shows where the problem accelerations may arise. Air-damping effects were ignored. 

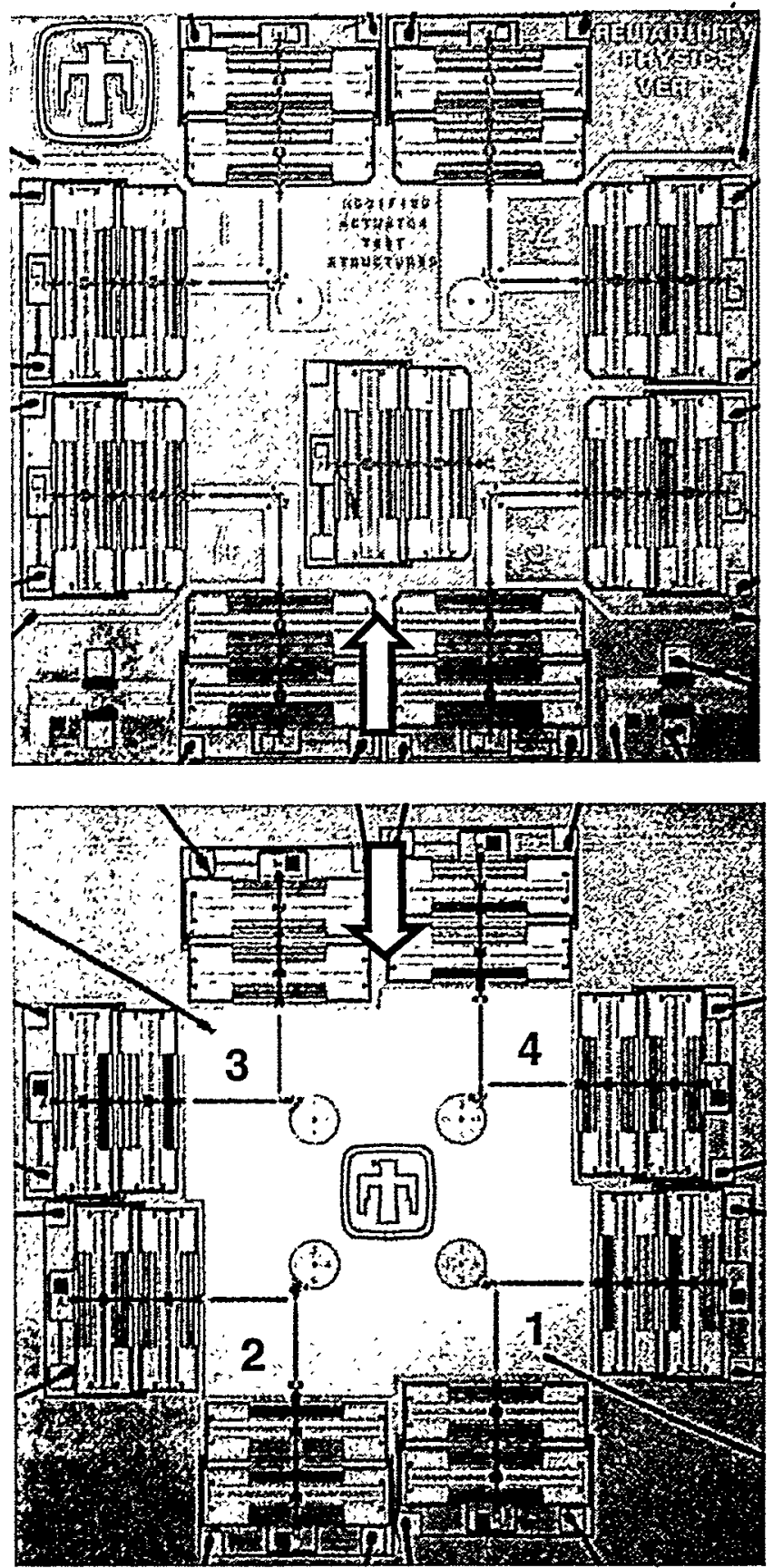

Figure 4. Upper - This die consists of two microengines driving load gears and two simple microengines. Lower - The other die used consists of four microengines driving load gears. The arrow indicates the direction of shock impact.

\section{Module description}

Two different designs of the basic microengine (shown in Figure 4) were subjected to shock. The lower die in the figure had four microengines driving load gears. This older version was found to have clamping of the electrostatic comb problems in the $Y$ actuator during operation [8], which prompted the newer design. The upper die in the figure consists of four newer-design microengines, two driving load gears and two without. The shuttle and comb fingers are slightly more massive and this microengine does not clamp. Another difference between the two designs was the use of vertical constraints (guides) in the new design. There was no vertical constraint in the old design.

\section{Sample Preparation}

Surface micromachined MEMS are mechanical structures fabricated from deposited thin films. The structures are encased in sacrificial layers (typically $\mathrm{SiO}_{2}$ ) until ready for use. The oxide film is etched by hydrofluoric acid (HF) to yield a "released" sample. There are several strong adhesive forces that act on the structures during the drying stage of the release [9]. These include capillary, electrostatic, and van der Waals forces. Capillary forces dominate at these dimensions and processes have been developed to reduce or eliminate these forces for successful operation of the MEMS structure [10].

Coupling agent coatings such as alkysilanes have been used to increase the hydrophobicity of the polysilicon surface, thus eliminating capillary forces [11,12]. Application of a coupling agent requires preparation of the polysilicon surface by an oxidation step $\left(\mathrm{H}_{2} \mathrm{O}_{2}\right)$, resulting in an oxide layer a few nanometers thick. The samples in this experiment were coated with an alkysilane coupling agent.

\section{Shock levels and spectral time response}

The calculations (Figure 3) gave guidance on what shock levels should be used. The experiment matrix with the total number of functioning microengines tested at each level is shown in Table 2. This total number was composed of two types of microengines as mentioned earlier.

Table 2. Number of microengines tested at each shock level.

\begin{tabular}{|c|c|c|c|}
\hline Level & Bottom & Top & Side \\
\hline $500 \mathrm{~g}$ & 8 & 8 & 8 \\
\hline $1,000 \mathrm{~g}$ & 7 & 8 & 7 \\
\hline $4,000 \mathrm{~g}$ & 4 & 5 & 3 \\
\hline $10,000 \mathrm{~g}$ & 5 & 8 & 6 \\
\hline $20,000 \mathrm{~g}$ & 6 & 7 & 6 \\
\hline $40,000 \mathrm{~g}$ & 4 & 8 & 4 \\
\hline
\end{tabular}

The MEMS devices were unpowered during the test. A maximum of four packages was clamped into a fixture as shown in Figure 5. The three orientations were achieved by rotating the fixture on the table. Because the acceleration sensors were too large to mount on the die itself, the fixture was instrumented with acceleration sensors

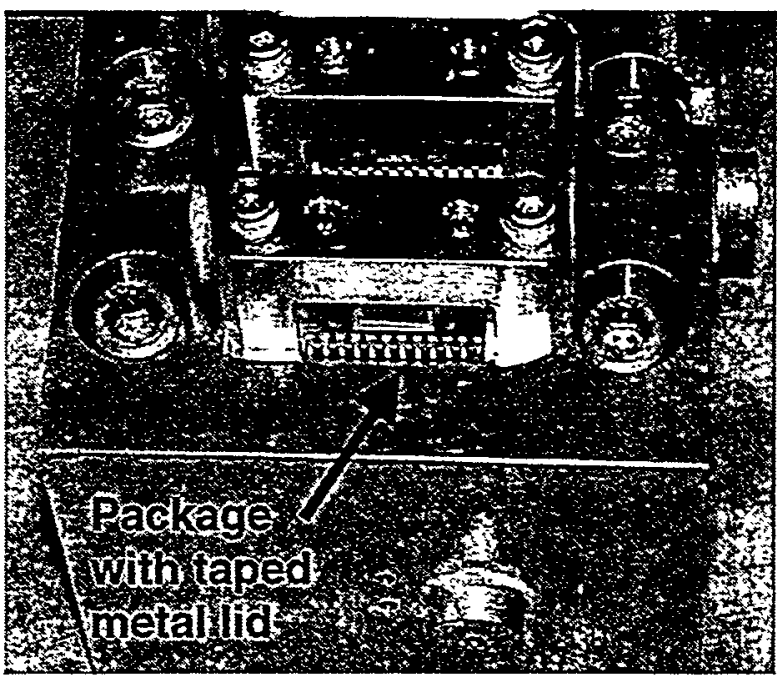

Figure 5. This fixture clamps up to four packages for the shock table tests. 


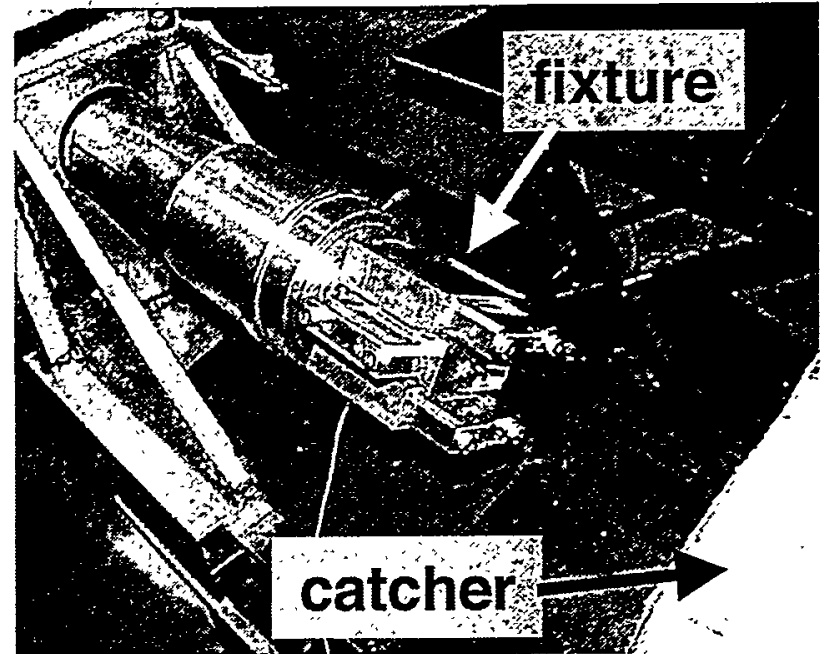

Figure 6. The fixture was mounted at the end of the Hopkinson bar and was launched into the catcher after the shock.

and then attached to the shock table. We believe that our clamping method allowed the shock impact to transfer through the fixturepackage interface. However, the shock level at the die may be lower than the measurements the sensors provided.

For shock levels $\geq 20,000 \mathrm{~g}$, a fixture was designed that attached to a Hopkinson bar. Two packages could be tested in two orientations at each shock level. The fixture is shown mounted to the end of the bar in Figure 6 . The shock actually launches the fixture off the end of the bar and into a foam-filled catcher.

The shock table produced the haversine shock pulses for levels $\leq$ $10,000 \mathrm{~g}$ with $1 \mathrm{~ms}$ pulse widths. For levels $\geq 20,000 \mathrm{~g}$, a Hopkinson bar produced pulse widths of roughly $0.2 \mathrm{~ms}$. Typical time responses from the acceleration sensors mounted to the fixture are shown in Figure 7. The ringing seen in the lower response was due to the fixture holding the packages.

\section{Microengine Shock Experiment}

Each module was attached inside a 24-pin DIP ceramic package. A typical package without a cover is shown in Figure 8. For the shock test, metal lids were taped to the packages to prevent particle contamination of the MEMS devices. We used three directions of shock impact designated top, bottom, and side, as shown in Figure 8.

Each functioning microengine was visually inspected and documented before the shock by capturing video images. We captured nine images per microengine. Four images were captured for each actuator, either $\mathrm{X}$ or $\mathrm{Y}$, corresponding to different sections of the shuttle and comb mechanism. The final image was of the gear.

The MEMS devices were unpowered during the test. Functionality was checked both before and after the shock test. The failure criterion was defined as the inability of the drive gear to make a complete revolution at the inspection frequency of $1 \mathrm{~Hz}$.

\section{RESULTS AND DISCUSSION}

Overall, results indicate that these MEMS devices are quite robust to shock. A full discussion of the results and failure analysis performed follows under each shock level. In every experiment, debris is mentioned and most of it was on the die prior to the shock. Although careful handling procedures have been used, manipulation of the die with tweezers during the release and packaging probably caused the debris. This debris likely originated from the edge of the

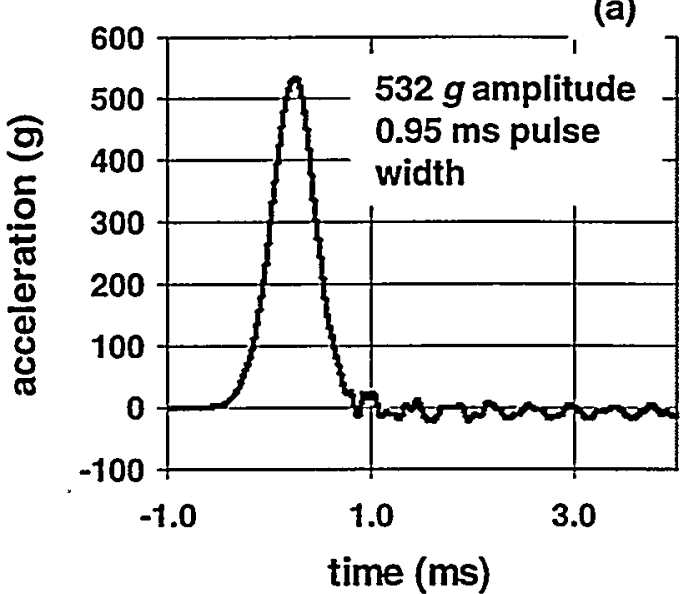

(b)

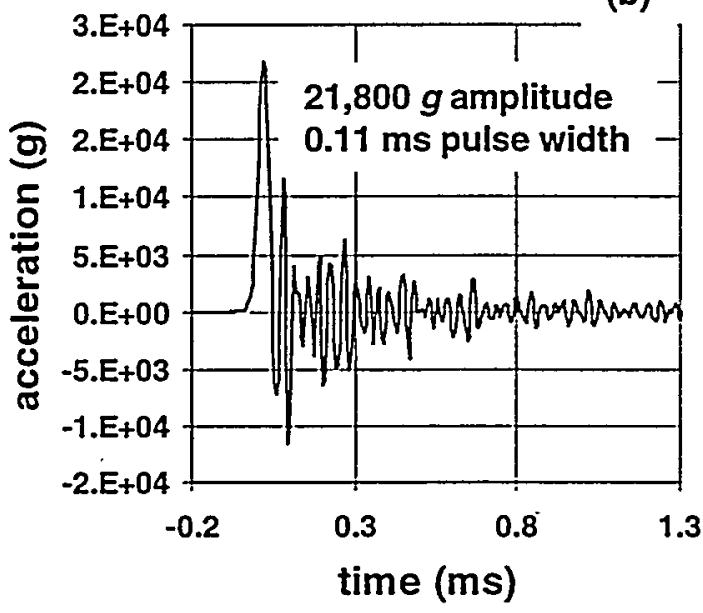

Figure 7. A typical time response a shock table impact is shown in (a). The time response from the Hopkinson bar (b) shows ringing after the initial shock pulse.

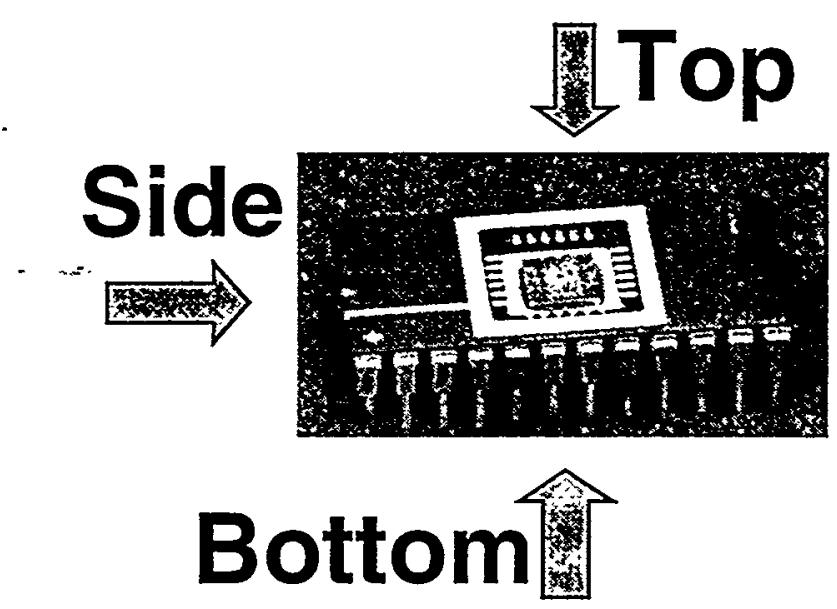

Figure 8. Photo of a typical packaged die that was shocked in the three orientations indicated. 
die, which has layers from the surface-micromachining process, that are exposed after sawing. The debris is a perfect candidate for shorting between the opposing comb fingers and the ground plane.

\section{$500 \mathrm{~g}$ and $1,000 \mathrm{~g}$}

Shock levels of $500 \mathrm{~g}$ and $1000 \mathrm{~g}$ did not provide enough force to even budge specks of debris on the die. All 24 microengines at $500 \mathrm{~g}$ and 22 microengines at $1,000 \mathrm{~g}$ exhibited no damage and functioned smoothly after the test. No stiction or comb misalignment was observed.

$4,000 \mathrm{~g}$

At $4000 \mathrm{~g}, 11$ out of 12 microengines functioned after the shock impact. Upon inspection, the debris on the surface of the die had moved slightly. We began to see bond wire problems in the package. There were two apparent failures that were unable to complete a revolution at $1 \mathrm{~Hz}$, but instead exhibited a rocking behavior. The microengines were later tested on a manual prober, thus bypassing the package. Both parts functioned properly indicating the failure was not in the MEMS device but rather somewhere in the package or wire bonding. Because we are interested only in microengine functionality and not packaging failures, the ability for the device to work on a manual prober was considered a successful pass of the shock test.

The one failed microengine from a side impact test moved slightly when first powered but then stuck. Manipulation of the microengine using probes failed in finding the source of the failure. Electrical probing of the drive signals revealed that some of the operational voltages were shorted to the ground plane. However, the shorting was due to our probing when we broke the $X$ shuttle, not due to a shock effect. We were unable to determine the failure mode for this microengine.

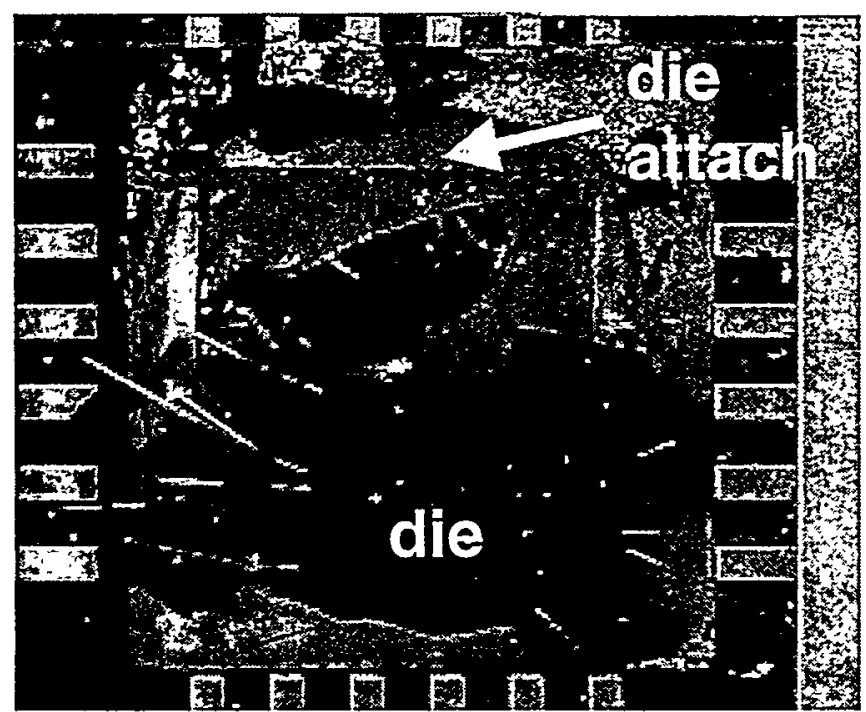

Figure 9. The interior of the package subjected to $10,000 \mathrm{~g}$ from top impact shows the broken die and the imprint of the die in the die attach.

\section{$10,000 g$}

Although the $10,000 \mathrm{~g}$ level had $90 \%$ pass the test ( 17 out of 19 ), we once again observed the rocking behavior, one from a top impact and one from a side impact. The side impact produced a hairline crack in the package, which propagated during handling to short two power signals. Cutting the bond wires eliminated the short and produced a functioning microengine when probed directly on the bond pads. The top-impact rocker simply functioned when manually probed indicating signal loss somewhere through the package.

The two failures at $10,000 \mathrm{~g}$ were on the same die subjected to top impact. The die actually broke away from the package and slammed into the metal lid. The broken die and package interior is shown in Figure 9. Note the imprint of the die in the die attach material. Each die was treated with a coupling agent to prevent stiction after the release. The failure occurred because the coupling agent weakened the adhesive strength at the die-package interface. This die attach failure was observed in only one package out of three subjected to top impact. Removal of the coupling agent from the back of the die before packaging should eliminate this problem.

Also at $10,000 \mathrm{~g}$, debris moved substantially. The edge of the die exposes polysilicon layers, which can flake off during handling to produce debris. The older-microengine-design die had beam-like alignment marks located near the streets, which were freed due to handling, producing debris. This debris has the potential to short out the actuators in the microengine by bridging the powered actuator to the ground plane.

\section{$20,000 \mathrm{~g}$}

Following shock testing at $20,000 \mathrm{~g}, 13$ out of 19 microengines were functioning, but we began to observe structural damage. Three large gears $(320-\mu \mathrm{m}$ diameter) broke away from the substrate as shown in Figure 10 due to a bottom impact. The microengines still

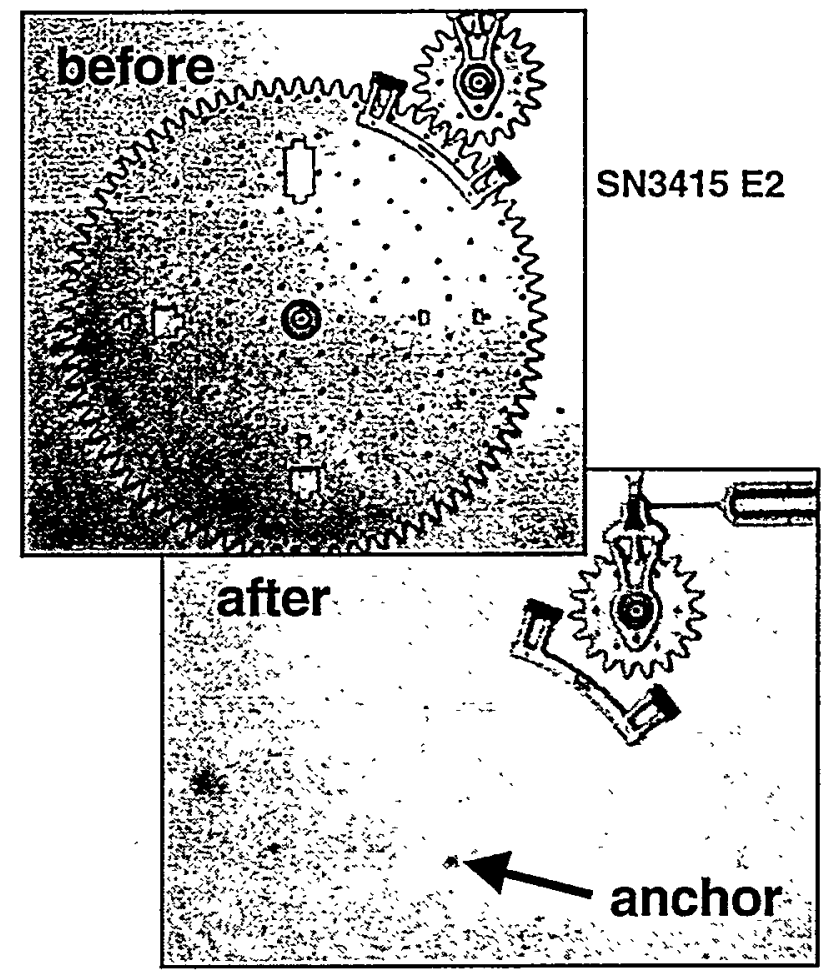

Figure 10. A bottom impact of $20,000 \mathrm{~g}$ broke the anchor of the large gear. The microengine still functioned in this case. 


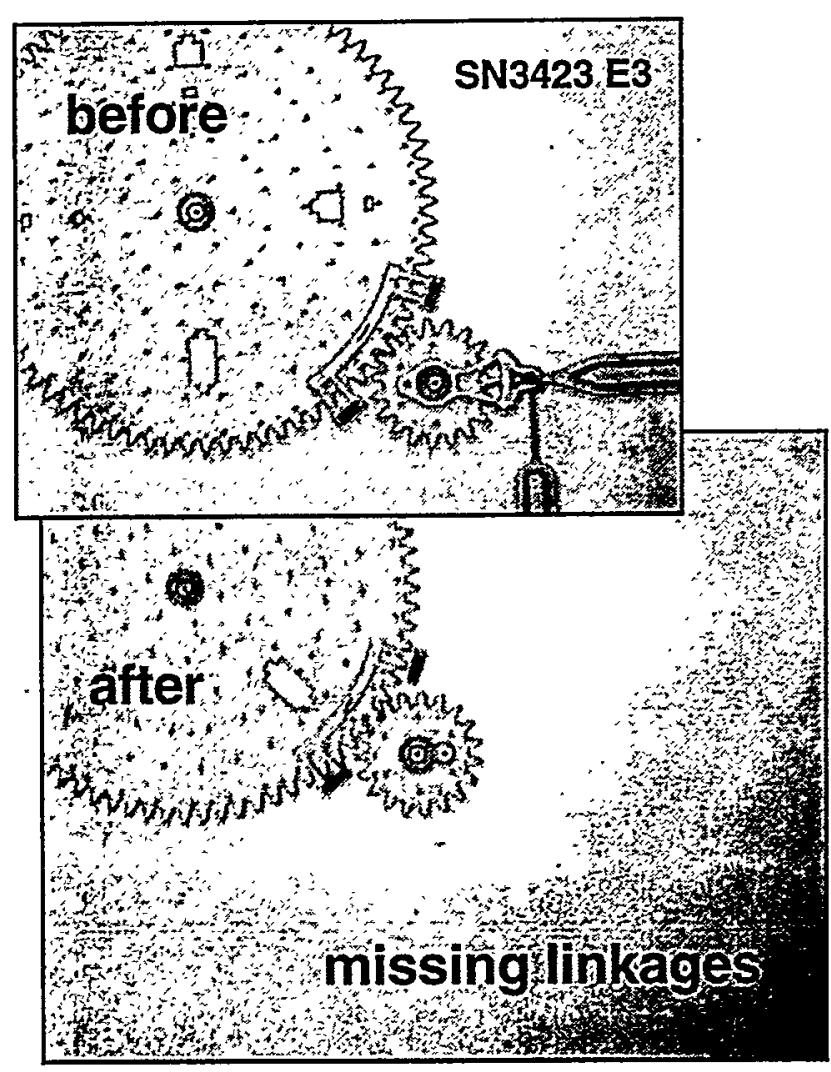

Figure 11. The linkage arms on one of the microengines broke with a $20,000 \mathrm{~g}$ top impact.

functioned after test, but this would have been a system failure if the large gear were necessary. A simple design change to make the anchor for the large gear larger and thus stronger would prevent the loss of the gear. The anchor diameter is now $14 \mu \mathrm{m}$, which is the same as the drive gear.

One set of linkages was lost (Figure 11) in a top impact producing a failed microengine. Here the shock was strong enough to fracture both the pin joints and the flexures between the linkage arms. The flexures are only $2 \mu \mathrm{m}$ wide and $40 \mu \mathrm{m}$ long and allow bending of the linkage arms to move the gear. Illustrated in Figure 12 are the pin joint and flexure respectively. A small piece of debris is located near the pin joint. It is unknown at this time if both regions failed simultaneously, if the pin joint fractured as a result of fracturing of the flexures, or vice versa. It can be stated that this level of shock is capable of breaking the thinner, more fragile regions of the microengine.

One of the microengines at $20,000 \mathrm{~g}$ subjected to top impact failed due to debris shorting out an actuator to the ground plane. Removal of the debris by careful probing eliminated the short. Removal of this debris permitted the microengine to function, indicating that it was the source of the short.

The other four failures at $20,000 \mathrm{~g}$ exhibited the rocking behavior mentioned earlier. Probing to bypass the package was unsuccessful in these cases to revive the microengine. However, electrical probing between the operational voltage pads and the ground plane revealed shorts in all four devices. SEM examination of these devices revealed two different shorting mechanisms. The first shorting phenomena as illustrated in Figure 13 reveals a particle bridging the powered actuator to the shuttle and the ground plane. Since polysilicon has been shown to fracture at these levels of shock, it is not surprising to see an electrical short resulting from particle contamination. This particle appears to have structure indicating that it may be due to fracture somewhere on the die.

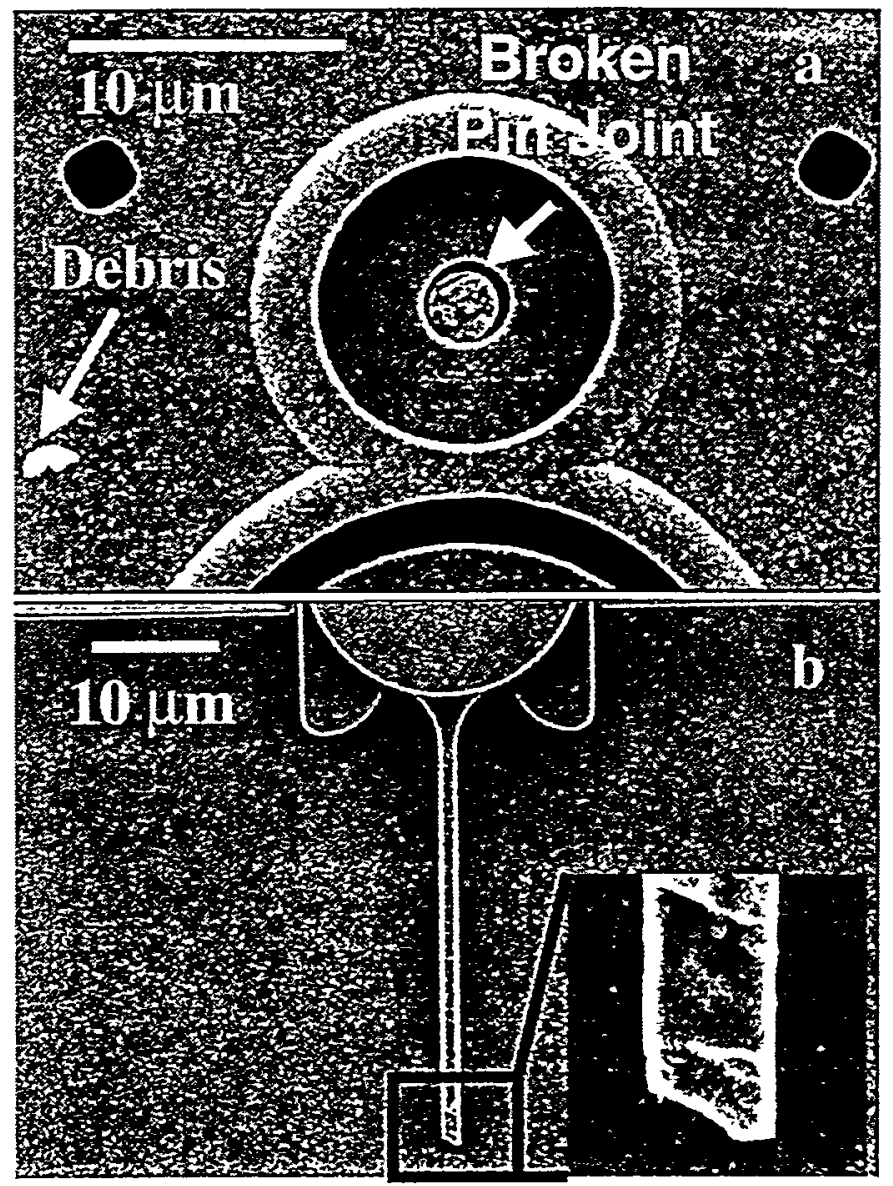

Figure 12. The broken pin joint (a) and fractured flexure (b) resulting from $20,000 \mathrm{~g}$ top impact shock are shown.

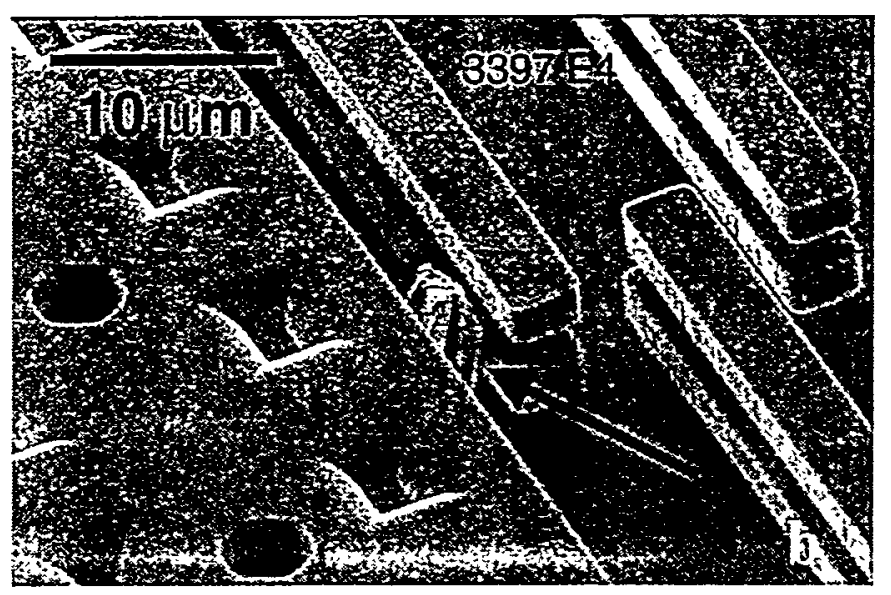

Figure 13. Particle contamination was found within the actuator region of the microengine subjected to a $20,000 \mathrm{~g}$ top impact. Note the contact between the particle, stationary comb fingers, and the shuttle resulting in electrical short of the drive signal to the ground plane.

The second shorting phenomena observed in this experiment, is a comb finger contacting the ground plane. This led to a direct short of this actuator. Electrical probing 'revealed the presence of the short, and visual inspection using the SEM revealed the bottom comb finger adhered to the ground plane as illustrated in Figure 14. 


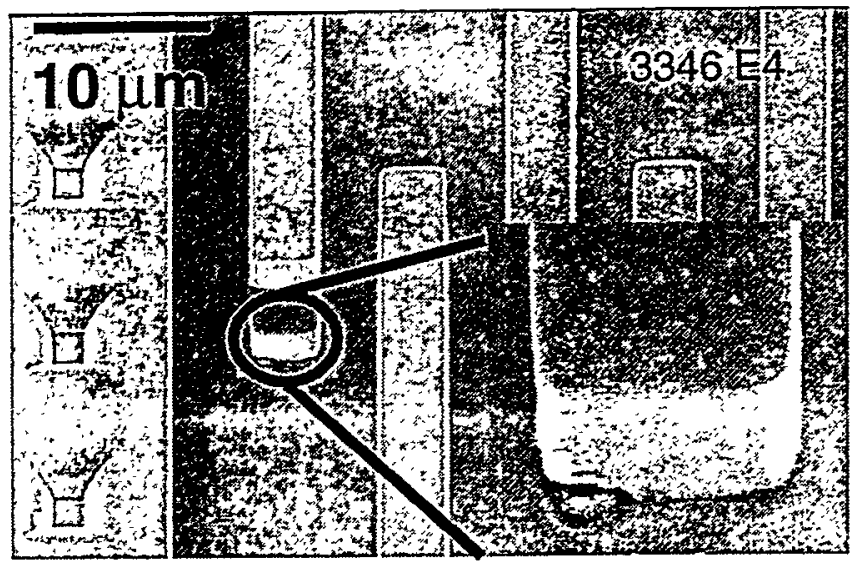

Figure 14. This stationary comb finger was observed stuck down to the ground plane after a top shock impact at $20,000 \mathrm{~g}$. Note the contact at the tip of the comb finger and the ground plane in the expanded image.

Could the shock have bent and adhered the fingers? If we examine a single lower comb finger with a length of $48 \mu \mathrm{m}$, width of 4 $\mu \mathrm{m}$, and thickness of $2.5 \mu \mathrm{m}$, we can calculate a mass of $1.1 \mathrm{ng}$. The force from a $20,000 \mathrm{~g}$ shock could be $0.22 \mu \mathrm{N}$. Now, we use an equation similar to equation. (3) except it is for a uniform load on a beam,

$$
\delta=w L^{4} / 8 E I
$$

where $w$ is the load or $F / L$. A deflection of $2 \mu \mathrm{m}$ where the tip of the finger would touch to ground plane requires a force of $117 \mu \mathrm{N}$. The force from the shock is almost three orders of magnitude below the force needed to bend the finger implying that the shock impact was not the cause of the short.

Additionally, after observing this short at $20,000 \mathrm{~g}$, we tested our controls that were kept in a benign nitrogen environment during the shock tests. Four out of nine microengine controls had failed, by exhibiting rocking behavior. Electrical probing revealed shorting of the operational voltages to the ground plane. SEM examination of the controls revealed the same signature of one or more fingers adhered to the ground plane. This result suggests that this failure mechanism was not induced by shock.

There were no severe die-attach failures at $20,000 \mathrm{~g}$ from top impact. In two packages the dies delaminated from the adhesive and were held in the package only by the bond wires. Upon probing manually, the microengines still functioned indicating they had not contacted the metal lid and fractured.

\section{$40,000 \mathrm{~g}$}

The extreme level of $40,000 \mathrm{~g}$ shattered all four of the ceramic packages. An example of package fracture after bottom impact is shown in Figure 15. The mounting method in the fixture may have contributed to the fracture. All 8 microengines stressed in a top impact were destroyed due to die attach failure. Surprisingly, two dice survived (one from bottom impact and one from side impact) and were lifted from the fractured packages. One is shown in Figure 16 where the bond wires are visible along the edge of the die. After careful removal of the bond wires, two microengines actually functioned, one from each die. There was a large amount of debris on the surfaces of each die (Figure 17), partly from the cracked packages.

The bottom impact test at $40,000 \mathrm{~g}$ started with four functioning microengines. After the test, one of the microengines functioned,

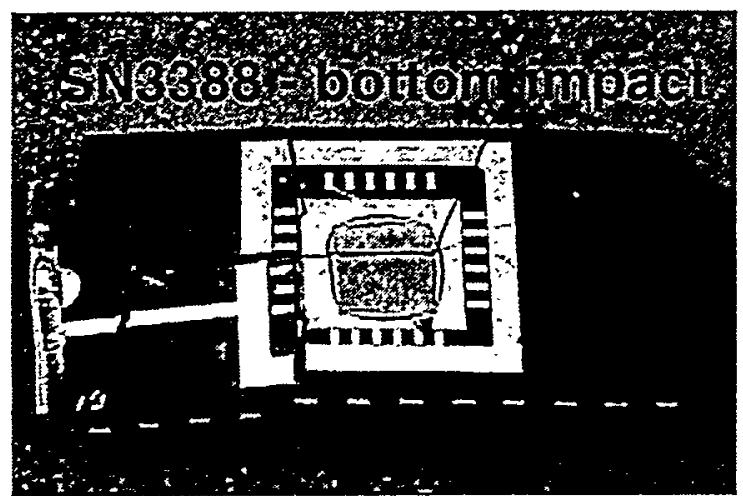

Figure 15. The $40,000 \mathrm{~g}$ impact from the bottom fractured the package. The die was removed and tested.

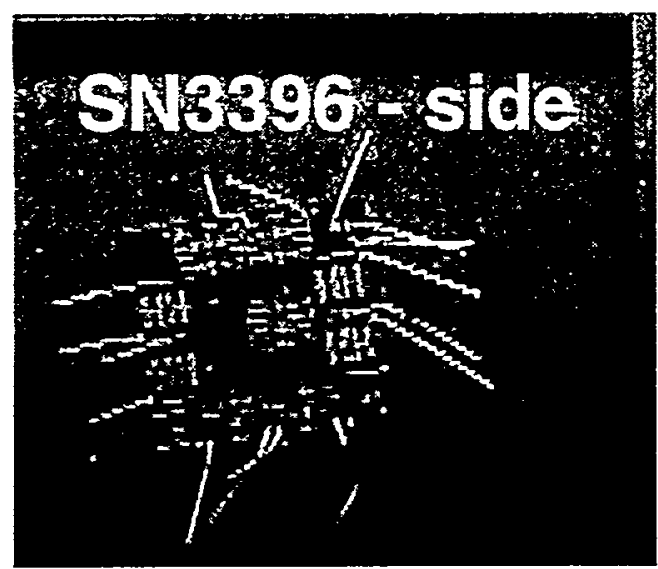

Figure 16. This die was removed from a fractured package subjected to $40,000 \mathrm{~g}$-shock impact.



Figure17. The particle contamination shown in this SEM image was characteristic to both dice that survived the $40,000 \mathrm{~g}$ impact. Specifically, this is the $y$-axis actuator from a side impact.

two of the microengines failed as rockers, and the other microengine was shorted due to debris. Closer inspection of the four microengines on this die revealed a significant amount of particulate contamination.

Characterization of the two microengines that failed as rockers revealed shorts between the operational voltage and the ground plane. One of the microengine failed due to debris contamination. The particle was located between the comb fingers and is illustrated 


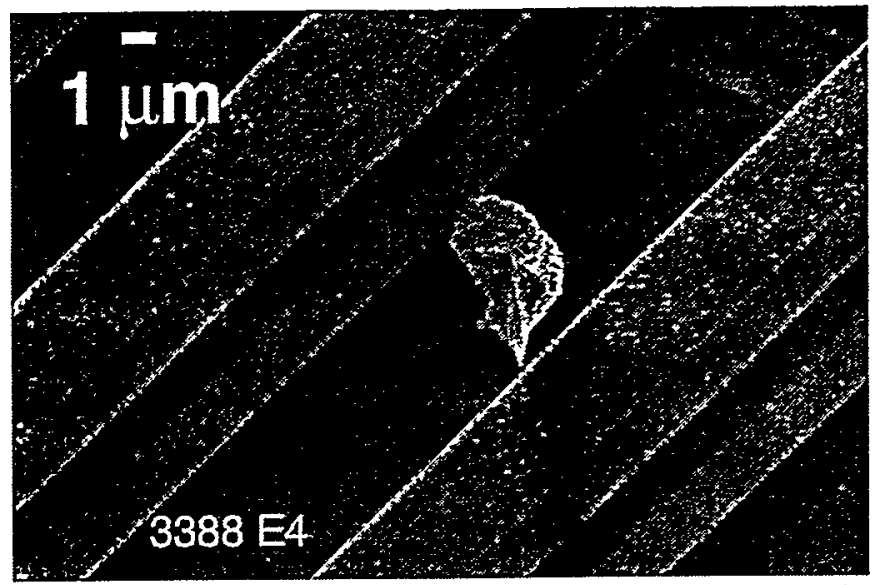

Figure 18. This particle was the short between the stationary comb finger and the ground plane. The shock impact was from the bottom at a $40,000 \mathrm{~g}$ level.

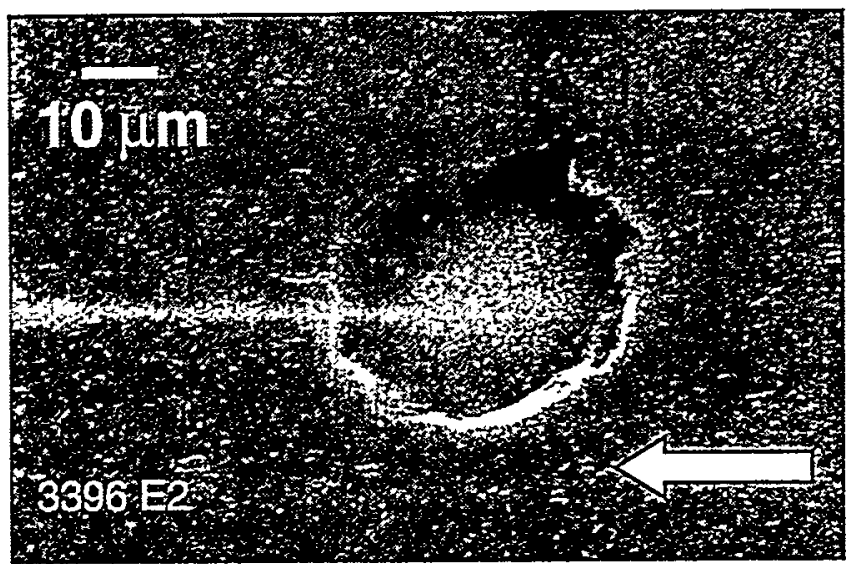

Figure 19. This crater resulted from a load gear anchor being ripped out of the polysilicon ground plane by a side shock impact of $40,000 \mathrm{~g}$. The arrow indicates the shock direction.

in Figure 18. The other rocking microengine had a stuck comb finger on the ground plane due to a bottom comb finger, similar to the electrical shorts found at $20,000 \mathrm{~g}$.

The fourth failed microengine had debris directly bridging the powered actuator to ground. We removed the debris with a probe tip, which permitted the microengine to work.

The side impact die at $40,000 \mathrm{~g}$ also started with four functioning microengines. After the test, one microengine functioned, two microengines had broken drive gear anchors, and the fourth microengine had a broken flexure.

The one microengine that functioned had its load gear ripped out of the ground plane. As illustrated in Figure 19, the crater left by the missing load-gear hub is charging up in the SEM. The surrounding ground plane is polysilicon and grounded through the bond wire. For this area to charge, the silicon nitride underneath the ground plane would have to be exposed. This would indicate the hub delaminated from the silicon nitride, but fractured around the perimeter of the hub.

One microengine failed with a broken drive gear hub also had a broken rear guide as shown in Figure 20. Of particular interest in this microengine was the observation that the shuttles along both $x$ and $y$ actuators are on top of the guides. We suspect that the combination of an unanchored drive gear and the lack of a guide removed some of the constraint and the shuttle could move within the $x$ and $y$ plane (plane of the microengine). The residual ringing in the shock

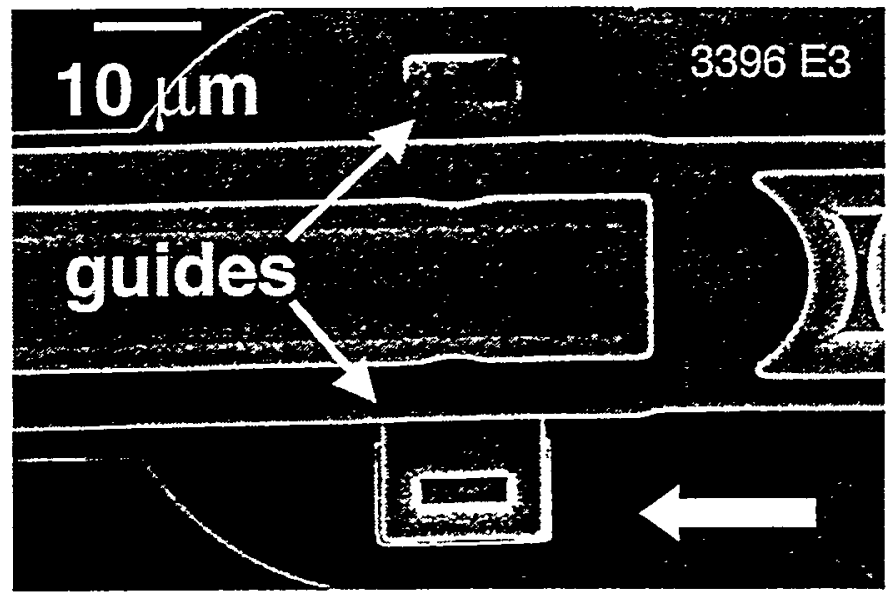

Figure 20. The 40,000g-shock impact broke one of the rear guides of this $\mathrm{X}$-axis shuttle. The shuttle now rides on top of the remaining guide.

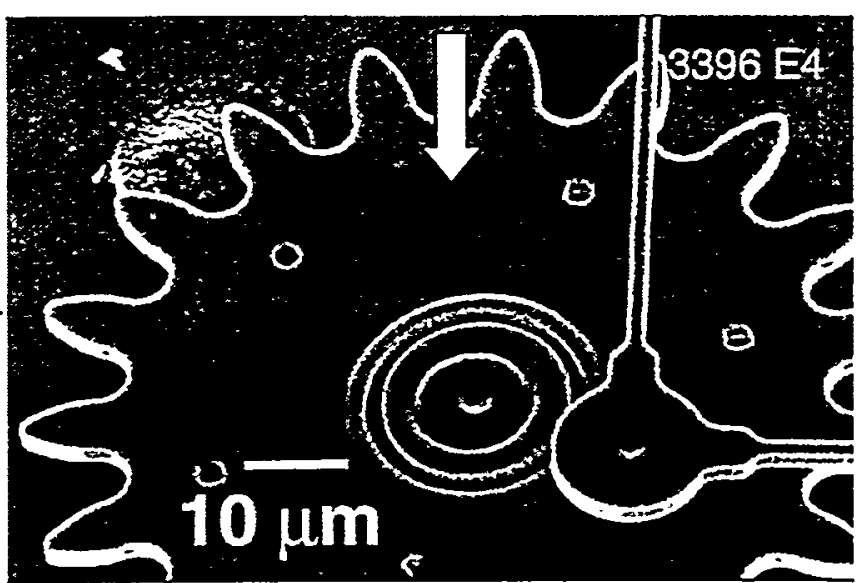

Figure 21. The drive gear anchor was broken by a side impact shock of $40,000 \mathrm{~g}$. The arrow indicates the direction of the impact.

wave may have caused motion or vibration of the linkage arms, leading to the shuttles landing on top of the guides.

The second microengine that failed due to a broken drive gear anchor (the actuators still worked) is shown in Figure 21. Note that the fracture did not expose the silicon nitride layer in this case. In this microengine, the shuttle also worked its way out of the guides, but only on the $y$ actuator.

The fourth microengine subjected to side impact failed due to a broken flexure in the linkage arms (again, the actuators work) and is shown in Figure 22. The flexure had a width of $1.7 \mu \mathrm{m}$, a thickness of $2.5 \mu \mathrm{m}$, and a length of $40 \mu \mathrm{m}$. Assuming that the massive comb structure pulled the flexure lengthwise, we calculated the force exerted on the flexure. With a $40,000 \mathrm{~g}$ shock and a $1.06-\mu \mathrm{g}$ comb structure, the force could be as high as $415 \mu \mathrm{N}$. The estimated force, $P$, to break the flexure due to tensile loading is

$$
P=\sigma A=17,000 \mu \mathrm{N}
$$

where $\sigma$ is the fracture strength and $A$ is the cross-sectional area of the beam. Fracture due to tensile loading required much more force than available, leading us to estimate the effect of buckling. Using Euler buckling load equations, the critical load, $P_{c r}$, is given by

$$
P_{c r}=\pi^{2} E I / L^{2}=2,200 \mu \mathrm{N}
$$

which is much closer to that calculated from the shock. There was ringing associated with this shock which could have led to additional buckling allowing the flexure to fracture. 




Figure 22. This SEM image shows the broken $X$ flexure occurring after side impact of $40,000 \mathrm{~g}$. The arrow indicates the direction of impact.

\section{Comparison to prediction}

The model used in the predictions considered the separate beams of the springs as a laminate. In actuality, the springs are stiffer because they are separated by $2 \mu \mathrm{m}$ and are anchored together in five places. To get an upper bound on the stiffness of the springs, we can assume that the gap between the two beams is filled with polysilicon. This beam would have an overall thickness of $6.75 \mu \mathrm{m}$. The spring constant $k$, in this case would be that of a simple cantilever beam

$$
k=3 E I / L^{3}
$$

Deflections, $\delta$, of the system would be

$$
\delta=F / 4 k=F L^{3} / I 2 E I
$$

Using equation (11) with the value of I for a 6.75 thick beam yields predictions of stiction at $400 \mathrm{~g}$, and misalignment at $2000 \mathrm{~g}$. Equation (6) yields a higher prediction for fracture at $16,300 \mathrm{~g}$.

Our prediction of stiction would then be between $80 \mathrm{~g}$ and $400 \mathrm{~g}$. We did not observe it during any of the shock impacts including $40,000 \mathrm{~g}$. The calculations that we performed neglected the effect of air between the shuttle and the ground plane. The air provides viscous damping, specifically squeeze-film damping [13] and is typically an order of magnitude greater than the damping between the comb fingers [14]. Additionally, the areas that would be most susceptible to stiction (the flat surface at the ends of the springs or the shuttle bottom) have dimples to prevent intimate surface to surface contact.

Misalignment was not observed at between $220 \mathrm{~g}$ and $2000 \mathrm{~g}$ probably because the moving shuttle was anchored down at the gear. At very high levels, $40,000 \mathrm{~g}$, we observed two cases where the shuttle was riding on top of the vertical constraints. We suspect that in this case, the ringing of the shock impact coupled to the loss of one guidepost and an unanchored drive gear allowed the shuttle to pop out of its constraints.

The prediction of fracture of the double-beamed springs was not seen between $8,100 \mathrm{~g}$ and $16,300 \mathrm{~g}$. However, fracture was seen in the damage to single layer structures at $20,000 \mathrm{~g}$ and above. The loss of the linkage arms involved fracture in three locations, the pin-joint and two flex joints.

We are not sure how much the package mitigated shock. For this experiment, the sensors were attached to the fixture. However, in light of the disagreement with prediction, the microengines could have seen a lower shock level than what we measured.

\section{CONCLUSIONS}

Overall, we have demonstrated that these MEMS devices are extremely robust in shock environments. At levels up to twenty times the typical requirement for our systems, some of the microengines functioned after test.

Debris from the die edges and alignment marks proved to be a reliability concern. It moved at levels greater than $10,000 \mathrm{~g}$ causing electrical shorts in the actuators and could have prevented movement by jamming up joints or linkages. Cleaning up the edge of the die or encasing the moving parts in another layer of polysilicon could mitigate the debris effect.

The coupling agent used to prevent stiction in the release may also pose a reliability concern in packaging these dice. The coupling agent weakened the bond between the die and the package. These failures can be reduced by removing the coupling agent from the backside of the die prior to packaging.

A more global concern for MEMS reliability at these shock levels resides in the package. As shown in Figure 15, the limiting factor in overall functionality will reside in the survival of the package itself. Utilizing plastic or non-ceramic packages may reduce or prevent these failures from occurring.

Perhaps the most surprising failures were those not related to shock, but due to shorted comb fingers to the ground plane. Results have shown that this failure mode occurred at $20,000 \mathrm{~g}$ and $40,000 \mathrm{~g}$, both levels that are not strong enough to pull down a single comb finger. Investigations are underway to determine the cause of the short. We suspect these shorted failures may be the result of handling of the packaged MEMS devices, or residual material present along the tips of the bottom comb fingers prior to testing.

Simple design changes such as larger anchors for large gears or wider flexures should strengthen the structure of these parts and allow high-g shocks to be routinely survived.

\section{ACKNOWLEDGMENTS}

The authors thank the personnel of the Microelectronics Development Laboratory at-SNL for fabricating, releasing, and packaging the devices used for this test. We acknowledge the help of Bill Eaton for macro writing to make the documentation easier, Jim Allen for damping discussions, David LaVan for beam mechanics and Alex Pimentel for the FIB cuts.

Sandia is a multiprogram laboratory operated by Sandia Corporation, a Lockheed Martin Company, for the United States Department of Energy under Contract DE-AC04-94-AL85000

\section{REFERENCES}

[1] S. J. Cunningham, D. G. McIntyre, J. S. Carper, P. D. Jaramillo, and W. Tang, "Microstructures designed for shock robustness," SPIE Proceedings, Vol. 2880, 1996, pp. 99-107.

[2] T. G. Brown and B. Davis, "Dynamic High-G Loading of MEMS Sensors: Ground and Flight Testing," SPIE Proceedings, Vol 3512, 1998, pp. 228-235.

[3] D. M. Tanner, et al., "The Effect of Humidity on the Reliability of a Surface Micromachined Microengine," Proc. of IRPS, 1999, pp. 189-197.

[4] S. T. Patton, W. D. Cowan, and J. S. Zabinski, "Performance and Reliability of a New MEMS Electrostatic Lateral Output Motor," Proc. of IRPS, 1999, pp. 179-188. 
[5] http://www.mdl.sandia.gov/Micromachine/

[6] E. J. Garcia and J. J. Sniegowski, "Surface micromachined microengine", Sensors and Actuators A, Vol. 48, 1995, pp. 203214.

[7] W. N. Sharpe, Jr., K. T. Tumer, and R. L. Edwards, "Tensile Testing of Polysilicon," Experimental Mechanics, vol. 39, no.. 3, 1999, pp. 162-170.

[8] S. L. Miller, M. S. Rodgers, G. LaVigne, J. J. Sniegowski, P. Clews, D. M. Tanner, K. A. Peterson, "Failure Modes in Surface Micromachined MicroElectroMechanical Actuators," Proc. of IRPS, Reno, NV, 1998, pp. 17-25.

[9] R. Maboudian and R. T. Howe, "Critical Review: Adhesion in surface micromechanic structures," Journal Vac. Sci. Technol., B 15(1), Jan/Feb 1997, pp. 1-20.

[10] R. Maboudian and R. T. Howe, "Stiction reduction processes for surface micromachines," Tribology Letters, 3, 1997, pp. 215-221.


On Solid-State Sensors and Actuators (Transducers '95) and Eurosensors IX, Vol.1 Stockholm, June 1995, pp. 210-213.

[12] R. L. Alley, R. T. Howe, and K. Komvopoulos, Proceedings of the IEEE Solid-State Sensor and Actuator Workshop, Hilton Head, SC, 1992, pp. 202-207.

[13] W. Griffin, H. Richardson, S. Yamanami, "A Study of squeeze film damping," ASME Journal of Basic Engineering, June 1966, pp. 451-456.

[14] M. A. Lemkin, "Micro Accelerometer Design with Digital Feedback Control," PhD Dissertation, University of Califormia, Berkeley, 1997, pp.11-15. 